\title{
A comment on some of the conclusions made by Delgado-Fernandez et al. (2019). "Is 're-mobilisation' nature conservation or nature destruction? A commentary".
}

\author{
Julie Creer ${ }^{1}$ (D) Emmer Litt ${ }^{1} \cdot$ John Ratcliffe $^{1} \cdot$ Sue Rees $^{2} \cdot$ Nick Thomas $^{1} \cdot$ Phil Smith $^{3}$
}

Received: 2 March 2020 /Revised: 2 March 2020 / Accepted: 6 April 2020 / Published online: 11 May 2020

(C) The Author(s) 2020

\section{Context and introduction to UK sand dune conservation management}

This reply is primarily from Natural Resources Wales (NRW) and Natural England (NE) in response to several references in Delgado-Fernandez et al. (2019) to the management undertaken by NRW in the past on Welsh sand dunes and future management planned under two EU funded LIFE projects for sand dune conservation in England and Wales. Both NRW and NE are statutory nature conservation bodies and as such have specific purposes:

- NRW's purpose is to "pursue sustainable management of natural resources" and "apply the principles of sustainable management of natural resources" as stated in the Environment (Wales) Act 2016.

- Natural England's purpose (as set out in the Natural Environment and Rural Communities Act 2006), is to ensure that the natural environment (land, flora and fauna, freshwater and marine environments, landscapes, geology, and soils) is conserved, enhanced and managed for the benefit of present and future generations, thereby contributing to sustainable development. It also has a responsibility to help people enjoy, understand and access the natural environment.

Julie Creer

julie.creer@cyfoethnaturiolcymru.gov.uk

1 Natural Resources Wales, Ty Cambria, 29 Newport Road, Cardiff CF24 0TP, UK

2 Natural England, County Hall, Spetchley Road, Worcester WR5 2NP, UK

3 9, Hayward Court, Watchyard Lane, Formby, Liverpool, England L37 3QP
Both bodies are bound under UK and European legislation to undertake the conservation management of habitats and species, specifically where they occur on designated sites, such as Sites of Special Scientific Interest (SSSI) and International sites such as Special Areas of Conservation (SAC), Special Protection Areas (SPAs and Ramsar sites).

UK sand dune conservation follows an ecosystem approach that forms the foundation of sustainable management. Conservation management to rejuvenate sand dune habitats maintains and enhances successional stages of sand dune habitats, thereby increasing and improving resilience and multiple ecosystem services provision.

\section{Sand dune stabilisation and species decline stimulates a change to 'traditional' sand dune conservation management}

Western European dunes are some of the most biologically rich and diverse ecosystems in the region due to the juxtaposition of contrasting and highly stressed microhabitats (wet and dry, stable and unstable, nutrient poor). DelgadoFernandez et al. (2019) recognise that coastal dune systems in the UK and many other parts of the world, are increasingly vegetated, and are therefore losing bare sand and dynamism, along with declines in the specialist flora and fauna requiring open conditions. The dune manager's response has shifted from the past emphasis on stabilisation to various forms of "rejuvenation". However, Delgado-Fernandez et al. (2019) postulate that, under the current prevailing climate, dunes in northwest Europe would be expected to support dense vegetation and that their historic mobile condition was initiated primarily by human activities. Delgado-Fernandez et al. (2019) advocate that, with the exception of non-native invasive plant control, current rejuvenation techniques, such as increased grazing, mowing, 'notching', and encouraging visitor access, are unnecessary and potentially damaging. They suggest that such actions may, for example, increase the risk of 
coastal erosion. Also, in their view, due to climatic factors, such interventions will not be sustainable but will need to be ongoing to maintain the desired condition, turning dune management into "expensive habitat engineering." Finally, they propose that dune management should focus on minimising human impacts and controlling visitor pressure, so that dunes can evolve "naturally".

Some of these assertions are arguably supportable. Thus, it is reasonable that large-scale works should only be considered as a last resort, as advocated by Pye et al. (2014): "As a general principle, human alteration of the landscape should be kept to a minimum and undertaken only in areas that have experienced significant human impact or where artificial structures and features impede natural processes. One option is to do nothing, hoping for a return to windier conditions. However, since the problem is essentially man-made and there are obligations to maintain designated features, rejuvenation measures should be tested in an attempt to reverse declines".

Remobilisation management has been attempted on relatively few European coastal dunelands where past human actions artificially forced stabilisation. The historic planting of Marram, Sea buckthorn and alien conifers, coupled with ongoing enhanced aerial deposition of nitrogen and other anthropogenic factors (such as re-engineering frontal dunes to create a barrier, even in areas where there is no risk of flooding), have negatively impacted natural coastal dune dynamism and biodiversity. Dune managers must ensure their sites deliver a range of services, including nature conservation (as outlined in UK and EU legislation), coastal risk management and recreation, as well as ensuring sites have resilience to climate change (Stratford et al. 2013; Van der Biest et al. 2017).

The Geological Conservation Review series in Britain recognises that naturally evolving dune systems have geomorphological value (May and Hansom 2003). The aim of remobilisation management is not to return to the desert-like conditions described 200 years ago (Ayton and Daniell 1978), but to encourage dynamic processes that have been halted through vegetation succession and artificial over-stabilisation. Re-mobilisation management aims to create a mosaic of vegetated dune with open, more dynamic patches that allow characteristic plant and animal communities to survive. These interventions will affect relatively small areas within individual dune systems.

Delgado-Fernandez et al. (2019) assert that, based on physical requirements, coastal dunes should be managed in a noninterventionist manner, allowing them to "seal" and evolve naturally. They emphasise the critical role of abiotic processes and that, because of cool temperatures and high precipitation, the dunes of the British coast can be expected to have low mobility. Therefore, attempts to rejuvenate are a "fight against natural evolutionary processes." While they acknowledge the importance of "some species" from an ecological standpoint, we feel that their emphasis on geomorphological considerations underplay the importance and complexity of sand- dune ecology (Howe et al. 2010, 2012) and the threat to biodiversity posed by "dune-sealing".

Delgado-Fernandez et al. (2019) question "the scientific basis for restoration of dunes as natural systems". There are several evidence sources reviewing the biodiversity and condition decline in dune systems, e.g., JNCC (2007, 2013, 2019) and Howe et al. $(2010,2012)$. EU, Defra and Welsh Government policies outline the need to conserve habitats and species, e.g., "halt the loss in biodiversity" (EU Biodiversity strategy to 2020), and "Protect habitats and species" under Nature Directives (EU Birds and Habitats Directives).

We recognise that sand dune condition follows a cyclical pattern with periods of instability. The length of this cycle can vary from decades to hundreds of years, depending on climatic conditions (Howe et al. 2012). The question is when the next period of instability will occur and, given the human induced acceleration of dune stabilisation and the greater wind energy required to disturb established vegetation, the prospects for species requiring bare sand and early successional stages are bleak.

\section{Conservation aims of re-mobilisation management}

The re-mobilisation management actions on sand dunes undertaken in several EU member states, including the UK, aim to restore dune processes that encourage mobile and early successional sand dune habitats, which are essential for the short and long-term survival of some of the UK's and EU's rarest species. There is good biological evidence (Brunbjerg et al. 2015; Howe et al. 2010) outlining the rarity and rapid decline of many species requiring bare sand or early successional conditions (e.g., EU Habitats Directive Annex II species Liparis loeselii, Petalophyllum ralfsii and Gentianella anglica and many UK nationally rare dune invertebrates). These species are at risk of extinction without ecological management interventions to provide conditions essential for their long-term survival. A quote by Daniel Janzen (1974) serves as a useful reminder that "what escapes the eye when species go extinct, is a much more insidious extinction - the extinction of ecological interactions". The complex combination of direct and indirect effects resulting from species interactions determines the fate of the remaining species (Montoya 2015). Thus, by ensuring that processes to maintain open habitats and unvegetated conditions across the range of successional stages on sand dunes occur, we are halting biodiversity loss and the wider reduction of ecological interactions. By intervening now, in a managed and monitored way, we will be able to ensure a degree of continuity for these species and processes; taking no action now could result in irreversible biodiversity losses. The authors' suggestion that "If dune management is focused on increasing the proportion of dune systems that 
are largely free of human impacts and are able to evolve naturally then this is likely to have the greatest benefit for all dune species" is not borne out by the evidence (JNCC 2007, 2013, 2019; Howe et al. 2010, 2012). DelgadoFernandez et al. (2019) acknowledge that "some species are important from an ecological point of view and that there may be areas where local vegetation removal could be considered in order to preserve flora and / or fauna that are rare and endangered regionally. Again, we would argue that this situation should occur rarely and should only be implemented after thorough evaluation of the evidence and potential impacts". UK experience suggests this loss of key species, indicative of ecosystem function and quality, is a much more common situation than the authors appreciate.

\section{Acknowledging the negative biodiversity effects of anthropogenic dune stabilisation}

Delgado-Fernandez et al. (2019) point to changes in dune vegetation as "natural" but decry the "destruction of inland habitats" by sand incursion, not recognising that for some species, bare sand is the natural habitat. They correctly identify that "Nature does not recognise good or bad" but fail to recognise that conservation management does apply values to nature and reaches decisions based on widely agreed protocols. They assume that simply not intervening is "natural" but fail to recognise that past human intervention has been integral to the development of dunes, whether it was the extermination of mega-fauna, the introduction of (non-native) rabbits, the increase in nitrogen (and ammonia) and carbon dioxide, the planting of Marram grass, the constriction of sediment supplies, or changes in climate. The question of what is natural is fundamental to their article but is not addressed. Conservationists frequently address problems caused by the effect of past human interventions and accept that most western European ecosystems are anthropogenic. The authors note that "Labelling a particular dune evolutionary stage (e.g., mobility) as 'natural' or 'desirable' seems arbitrary and vague, especially within the context of anthropogenic land uses of European dunes going back hundreds of years..." but fail to acknowledge that accepting today's conditions as natural or desirable is equally arbitrary. In the end, it is a valuebased decision, albeit informed by science; a challenge that conservation managers address every day.

\section{Concluding remarks}

The climate and nature emergency is the greatest environmental challenge to biodiversity conservation the world has ever faced (Haight and Hammill 2020), with coastal habitats being at the front-line of the effects of climate change. The impacts of climate change are not fully understood but are likely to be complex across all habitat types, especially dunes (Burden et al. 2020). In order to conserve biodiversity and ensure resilience of these habitats to the whole range of future scenarios, human intervention will be required to facilitate adaptation (in the right place and at the right time). Whether current techniques of dune rejuvenation are sustainable in the longer term is still to be fully evaluated, and evidence from earlier Dutch projects and the more recent work in Wales (at Newborough, Kenfig, and Merthyr Mawr) should help to provide answers. This urgency to conserve sand dunes and associated biodiversity has been recognised by the EU, funding two major dune conservation projects in the UK (Sands of LIFE - Wales and DuneLIFE - England). The aim of undertaking these projects is that key sand dune sites in the UK will be sustainably managed, have a better chance of maintaining dynamism, supporting essential ecosystem services, and remain as biologically rich and diverse ecosystems. The need to understand when, and how, to intervene sustainably in the underpinning physical processes essential for biological features is an important aspect of these conservation projects.

Open Access This article is licensed under a Creative Commons Attribution 4.0 International License, which permits use, sharing, adaptation, distribution and reproduction in any medium or format, as long as you give appropriate credit to the original author(s) and the source, provide a link to the Creative Commons licence, and indicate if changes were made. The images or other third party material in this article are included in the article's Creative Commons licence, unless indicated otherwise in a credit line to the material. If material is not included in the article's Creative Commons licence and your intended use is not permitted by statutory regulation or exceeds the permitted use, you will need to obtain permission directly from the copyright holder. To view a copy of this licence, visit http://creativecommons.org/licenses/by/4.0/.

\section{References}

Ayton R, and Daniell W (1978) A voyage round Great Britain undertaken between the years 1813 and 1823 and commencing from the Land's end, Cornwall. 2:97-105. Facsimile, Tate gallery and scholar press, London

Brunbjerg AK, Jørgensen GP, Nielsen KM, Pedersen ML, Svenning J, Ejrnæs R (2015) Disturbance in dry coastal dunes in Denmark promotes diversity of plants and arthropods. Biol Conserv 182:243-253

Burden A, Smeaton C, Angus S, Garbutt A, Jones L, Lewis HD, Rees SM (2020) Impacts of climate change on coastal habitats relevant to the coastal and marine environment around the UK. MCCIP Science Review 2020:228-255

Delgado-Fernandez I, Davidson-Arnott RGD, Hesp PA (2019) Is 'remobilisation' nature restoration or nature destruction? A commentary. J Coast Conserv 23 issue 6:1093-1103

Haight J, Hammill E (2020) Protected areas as potential refugia for biodiversity under climatic change. Biol Conserv 241:108258

Howe MA, Knight GT, Clee C (2010) The importance of coastal sand dunes for terrestrial invertebrates in Wales and the UK, with 
particular reference to aculeate Hymenoptera (bees, wasps \& ants). J Coast Conserv 14:91-102

Howe M, Litt E, Pye K (2012) Rejuvenating Welsh dunes. British Wildlife 24:85-94

Janzen DH (1974) The deflowering of Central America. Nat Hist 83:4853

JNCC (2007) 2nd UK Report on Implementation of the Habitats Directive. https://webarchive.nationalarchives.gov.uk/ 20180804091020/http://jncc.defra.gov.uk/page-4060

JNCC (2013) 3rd UK Habitats Directive Reporting 2013. https:// webarchive.nationalarchives.gov.uk/20180804090005/http://jncc. defra.gov.uk/page-6387

JNCC (2019) Article 17 Habitats Directive Report 2019: Habitat Conservation Status Assessments. https://jncc.gov.uk/our-work/ article-17-habitats-directive-report-2019-habitats/
May V. J, Hansom J. D (2003) Coastal Geomorphology of Great Britain, Geological Conservation Review Series, No. 28, Joint Nature Conservation Committee, Peterborough, 754 pp.

Montoya J. M (2015) Ecology: dynamics of indirect extinction. Current biology 25, Issue 23:R1129-R1131

Pye K, Blott SJ, Howe MA (2014) Coastal dune stabilization in Wales and requirements for rejuvenation. J Coast Conserv 18:27-54

Stratford CJ, Robins NS, Clarke D, Jones L, Weaver G (2013) An ecological review of dune slacks on the west coast of England and Wales. Ecohydrology 6:162-171

Van der Biest K, De Nocker L, Provoost S, Boerema A, Staes J, Meire P (2017) Dune dynamics safeguard ecosystem services. Ocean Coast Manag 149:148-158

Publisher's note Springer Nature remains neutral with regard to jurisdictional claims in published maps and institutional affiliations. 